\title{
Depolymerization of Pine Ethanol Lignin in the Medium of Supercritical Ethanol in the Presence of Catalysts $\mathrm{NiCu} / \mathrm{SiO}_{2}$ and $\mathrm{NiCuMo} / \mathrm{SiO}_{2}$
}

\author{
Angelina V. Miroshnikova*a, \\ Sergey V. Baryshnikova, Yuriy N. Malyara, \\ Vadim A. Yakovlev ${ }^{b}$, Oxana P. Taran ${ }^{a, b, c}$, \\ Laurent Djakovitch $^{\mathbf{d}}$ and Boris N. Kuznetsov ${ }^{\mathrm{a}, \mathrm{c}}$ \\ anstitute of Chemistry and Chemical Technology SB RAS \\ FRC "Krasnoyarsk Science Center SB RAS" \\ Krasnoyarsk, Russian Federation \\ ${ }^{b}$ Boreskov Institute of Catalysis SB RAS \\ Novosibirsk, Russian Federation \\ 'Siberian Federal University \\ Krasnoyarsk, Russian Federation \\ ${ }^{d}$ Institute of Research on Catalysis and the Environment of Lyon \\ Lyon, France
}

Abstract. The regularities of thermocatalytic transformation of pine ethanol lignin in supercritical ethanol in the presence of catalysts $\mathrm{NiCu} / \mathrm{SiO}_{2}$ and $\mathrm{NiCuMo} / \mathrm{SiO}_{2}$ in the temperature range $250-400{ }^{\circ} \mathrm{C}$ were established. The composition and structure of ethanol lignin, liquid and solid products of its conversion were studied by methods of elemental analysis and gel-permeating chromatography (GPC). The composition of gaseous products - by method of gas chromatography.

At the process temperature of $250{ }^{\circ} \mathrm{C}$ the catalysts do not have a significant effect on conversion of ethanol lignin. The maximal yield of liquid products $\left(83.5 \mathrm{wt}\right.$. \%) was obtained at temperature $300{ }^{\circ} \mathrm{C}$ in the presence of catalyst $\mathrm{NiCuMo} / \mathrm{SiO}_{2}$ containing $8.8 \mathrm{wt} . \%$ of molybdenum. At temperature $350{ }^{\circ} \mathrm{C}$ $\mathrm{NiCu} / \mathrm{SiO}_{2}$ and $\mathrm{NiCuMo} / \mathrm{SiO}_{2}$ catalysts contribute to the almost complete conversion of ethanol lignin into liquid and gaseous products, and the yield of solid products does not exceed $1 \mathrm{wt}$. \%.

In liquid products of catalytic conversion there is a decrease in the atomic ratio of $\mathrm{O} / \mathrm{C}$ and the increase of $\mathrm{H} / \mathrm{C}$ atomic ratio as compared to initial ethanol lignin due to catalytic intensification of reactions of deoxygenation and hydrogenation of lignin and products of its depolymerization.

(C) Siberian Federal University. All rights reserved

This work is licensed under a Creative Commons Attribution-NonCommercial 4.0 International License (CC BY-NC 4.0)

* Corresponding author E-mail address: miroshnikova.av@icct.krasn.ru 
According to GPC data on the curves of molecular mass distribution (MMD) of liquid products of thermocatalytic conversion of ethanol lignin at $300{ }^{\circ} \mathrm{C}$ there are peaks with highs at 160 and $380 \mathrm{Da}$, probably related to guiacyle monomers and dimmers, respectively.

From the comparison of MMD of liquid products obtained by ethanol lignin depolymerization at $300{ }^{\circ} \mathrm{C}$ over catalysts $\mathrm{NiCu} / \mathrm{SiO}_{2}$ and $\mathrm{NiCuMo} / \mathrm{SiO}_{2}$ it follows, that the introduction of molybdenum in the catalyst promotes the formation of monomeric guaiacyl products.

Keywords: pine ethanol lignin, supercritical ethanol, thermo-catalytic conversion, catalysts, $\mathrm{NiCu} /$ $\mathrm{SiO}_{2}, \mathrm{NiCuMo} / \mathrm{SiO}_{2}$, liquid products.

\title{
Деполимеризация этаноллигнина древесины сосны \\ в среде сверхкритического этанола \\ в присутствии катализаторов $\mathrm{NiCu} / \mathrm{SiO}_{2}$ и $\mathrm{NiCuMo} / \mathrm{SiO}_{2}$
}

\author{
А.В. Мирошникова ${ }^{a}$, С.В. Барышников ${ }^{a}$, \\ Ю.Н. Маляра ${ }^{a}$ В.А. Яковлев ${ }^{\sigma}$, \\ О.П. Таран ${ }^{\mathrm{a}, \tilde{,}, \mathrm{s}}$, Л. Дьякович ${ }^{\mathrm{r}}$, Б.Н. Кузнецов ${ }^{\mathrm{a}, \mathrm{B}}$ \\ ${ }^{a}$ Институт химии и химической технологии СО РАН \\ ФИЦ «Красноярский научный иентр СО РАН» \\ Российская Федерачия, Красноярск \\ ${ }^{6}$ Институт катализа им. Г.К. Борескова СО РАН \\ Российская Федерачия, Новосибирск \\ ${ }^{6}$ Сибирский федеральный университет \\ Российская Федерачия, Красноярск \\ `Институт исследований катализа и окружающей среды \\ Франияи, Лион
}

Аннотащия. Изучены закономерности термокаталитического превращения этаноллигнина сосны в сверхкритическом этаноле в присутствии катализаторов $\mathrm{NiCu} / \mathrm{SiO}_{2}$ и $\mathrm{NiCuMo} / \mathrm{SiO}_{2}$ в интервале температур $250-400{ }^{\circ} \mathrm{C}$. Состав и структура этаноллигнина, жидких и твердых продуктов его превращения исследованы методами элементного анализа и гельпроникающей хроматографии (ГПХ). Состав газообразных продуктов - методом газовой хроматографии. При температуре процесса $250{ }^{\circ} \mathrm{C}$ катализаторы не оказывают значительного влияния на конверсию этаноллигнина. Максимальный выход жидких продуктов (83,5 мас. \%) получен при температуре процесса $300{ }^{\circ} \mathrm{C}$ в присутствии катализатора $\mathrm{NiCuMo} / \mathrm{SiO}_{2}$ с содержанием молибдена 8,8 мас. \%. При температуре $350{ }^{\circ} \mathrm{C}$ катализаторы $\mathrm{NiCu} / \mathrm{SiO}_{2}$ и $\mathrm{NiCuMo} / \mathrm{SiO}_{2}$ 
способствуют практически полному превращению этаноллигнина в жидкие и газообразные продукты, а выход твердых продуктов не превышает 1 мас. \%.

В жидких продуктах каталитической конверсии этаноллигнина наблюдается значительное снижение атомного отношения $\mathrm{O} / \mathrm{C}$ и увеличение отношения $\mathrm{H} / \mathrm{C}$ по сравнению с исходным этаноллигнином вследствие протекания каталитических реакций деоксигенации и гидрирования этаноллигнина и продуктов его деполимеризации.

По данным ГПХ на кривых молекулярно-массового распределения (ММР) жидких продуктов термокаталитической конверсии этанолигнина при $300{ }^{\circ} \mathrm{C}$ появляются пики с максимумами в областях 160 и 380 Да, вероятно относящиеся к гваяцильным мономерам и димерам соответственно.

Из сопоставления молекулярно-массового распределения жидких продуктов, полученных деполимеризацией этаноллигнина при $300{ }^{\circ} \mathrm{C}$ на катализаторах $\mathrm{NiCu} / \mathrm{SiO}_{2}$ и $\mathrm{NiCuMo} / \mathrm{SiO}_{2}$ следует, что введение молибдена в состав катализатора интенсифицирует реакции образования мономерных гваяцильных продуктов.

Ключевые слова: этаноллигнин сосны, сверхкритический этанол, термокаталитическая конверсия, катализаторы, $\mathrm{NiCu} / \mathrm{SiO}_{2}, \mathrm{NiCuMo} / \mathrm{SiO}_{2}$, жидкие продукты.

Цитирование: Мирошникова, А.В. Деполимеризация этаноллигнина древесины сосны в среде сверхкритического этанола в присутствии катализаторов $\mathrm{NiCu} / \mathrm{SiO}_{2}$ и $\mathrm{NiCuMo} / \mathrm{SiO}_{2}$ / А.В. Мирошникова, С.В. Барышников, Ю.Н. Маляр, B.А. Яковлев, О.П. Таран, Л. Дьякович, Б.Н. Кузнецов // Журн. Сиб. федер. ун-та. Химия, 2020. 13(2). С. $247-259$. DOI: $10.17516 / 1998-2836-0179$

\section{Введение}

Лигноцеллюлозная биомасса является экологически безопасным, возобновляемым ресурсом для производства биотоплив и химических веществ. Лигнин - один из трех основных компонентов растительной биомассы, содержание которого в древесине достигает 30 мас. \%, что составляет около $40 \%$ ее энергетического потенциала [1-3]. Лигнины хвойных пород содержат более 85 мас. \% структур гваяцильного типа с небольшим количеством структур р-гидроксифенильного типа. Лигнины лиственных пород на 70 \% состоят из структурных компонентов сирингильного типа, а также небольшого количества гваяцильных компонентов [4]. Мономеры лигнина в макромолекуле связаны между собой С-О- и С-С-связями. Менее устойчивыми являются $\alpha-O-4-$ и $\beta-O-4-$ связи [5]. Различие в строении и составе лигнинов оказывает значительное влияние на термические свойства и состав продуктов, образующихся при их переработке. Лигнин гваяцильной природы более термически устойчив по сравнению с лигнином сирингильной природы [6, 7].

Традиционные процессы, реализованные на предприятиях целлюлозно-бумажной и гидролизной промышленности, позволяют отделить лигнин от полисахаридов (целлюлозы и гемицеллюлоз) путем варки в присутствии коррозионно-активных и экологически опасных реагентов. В этих условиях нативный лигнин полимеризуется, взаимодействует с серой и становится устойчивым для дальнейшей переработки в востребованные продукты [8]. Эффективным методом выделения лигнина без использования минеральных кислот и оснований является экстракция лигноцеллюлозных материалов легкокипящими органическими растворителями

$$
-249-
$$


либо их смесями с водой в интервале температур $180-200{ }^{\circ} \mathrm{C}$ [9]. Получаемые органосольвентные лигнины не содержат серу, имеют невысокую молекулярную массу и более высокую реакционную способность по сравнению с техническими лигнинами. Дальнейшая трансформация органосольвентных лигнинов в химические соединения с низкой молекулярной массой может быть осуществлена методами термического превращения в органических растворителях или в их смесях с водой при температурах $250-400{ }^{\circ} \mathrm{C}$. Использование низших алифатических спиртов, находящихся в сверхкритическом состоянии, позволяет увеличить выход экстрагируемых продуктов из лигнинов [4, 10-13]. Выбор спиртов обусловлен тем, что значения их критических температур ниже либо близки к оптимальным температурам термической деструкции лигнина. В процессе термического растворения спирты не только экстрагируют продукты термической фрагментации лигнина, но и способны их алкилировать, предотвращая вторичные реакции образования высокомолекулярных веществ [10]. Кроме того, спирты могут служить источником водорода, что позволяет в присутствии катализаторов осуществлять гидрогенолиз и гидрирование ароматических фрагментов макромолекул лигнина [11-13].

Использование твердых катализаторов на основе металлов платиновой группы (Pd, Ru, $\mathrm{Pt}$ ), нанесенных на $\mathrm{Al}_{2} \mathrm{O}_{3}, \mathrm{SiO}_{2}$, цеолиты или углеродные носители, позволяет интенсифицировать деполимеризацию лигнина и существенно увеличить выход жидких продуктов [1416]. Однако для практического применения более перспективны недорогие $\mathrm{Ni}$-содержащие катализаторы.

Для близкого по природе субстрата и условиям проведения процесса гидродеоксигенирования бионефти разработаны биметаллические катализаторы $\mathrm{NiCu} / \mathrm{SiO}_{2}$ с высоким содержанием активного компонента - Ni (37-58 мас. \%) [17]. Добавки меди применяли в качестве промотора для снижения температуры восстановления оксида никеля. Показано, что при $320^{\circ} \mathrm{C}$ и начальном давлении водорода 17 МПа эти катализаторы ускоряют реакции деоксигенирования гваякола и гидрирования ароматического кольца. Модифицирование катализаторов добавками молибдена приводит к снижению выхода кокса в процессах гидродеоксигенирования гваякола [18].

Ранее нами исследовано термическое превращение ацетонлигнина древесины осины в среде сверхкритического бутанола в присутствии катализаторов $\mathrm{NiCu} / \mathrm{SiO}_{2}[19]$ и $\mathrm{NiCuMo} / \mathrm{SiO}_{2}$ [20]. Показано, что при температуре процесса $300{ }^{\circ} \mathrm{C}$ в присутствии этих катализаторов выход гексанрастворимых продуктов увеличивается до 2,4 раз и в 3,3 раза снижается выход твердого остатка.

В настоящей работе изучены закономерности процесса термокаталитического превращения этаноллигнина сосны в среде сверхкритического этанола в присутствии катализаторов $\mathrm{NiCu} / \mathrm{SiO}_{2}$ и $\mathrm{NiCuMo} / \mathrm{SiO}_{2}$ (с различным содержанием молибдена) при температурах 300 и $350{ }^{\circ} \mathrm{C}$.

\section{2. Экспериментальная часть}

\section{1. Выделение этаноллигнина из древесины сосны}

Для получения этаноллигнина использовали древесину сосны сибирской (Pinus sibirica), содержащую ( \% в расчете на массу абсолютно сухой древесины): 47,6 - целлюлозы; 28,0 - лигнина; 16,5 - гемицеллюлоз; 7,6 - экстрактивных веществ; 0,3 - золы. Древесину измельчали на 
дезинтеграторе РМ-120 роторно-ножевого типа и отбирали фракцию с размером частиц менее 0,5 мм, содержание которой в измельченной древесине превышало 90 мас. \%. Извлечение этаноллигнина проводили при температуре $190{ }^{\circ} \mathrm{C}$ по методике [21]. Выход этаноллигнина составил 9,8 мас. \% или 36,7 мас. \% от содержания лигнина Класона в исходной древесине сосны.

\section{2. Приготовление и исследование катализаторов}

Катализаторы $\mathrm{NiCu} / \mathrm{SiO}_{2}$ и $\mathrm{NiCuMo} / \mathrm{SiO}_{2}$ готовили в лабораторных условиях золь-гель- методом [17].

Для получения катализатора $\mathrm{NiCuMo} / \mathrm{SiO}_{2}$ соответствующие количества коммерческого гидрата основного карбоната никеля (II), основного карбоната меди (II) и оксида молибдена (VI) смешивали с необходимым количеством водного раствора аммиака $\left(25 \% \mathrm{NH}_{3}\right)$ и бидистиллированной воды при постоянном перемешивании. Затем полученную суспензию фильтровали, сушили на воздухе в течение ночи при $120^{\circ} \mathrm{C}$ и прокаливали при $400{ }^{\circ} \mathrm{C}$ в течение 4 ч. Полученную смесь оксидов никеля, меди и молибдена фракционировали, фракцию с размером частиц до 2-5 мм пропитывали этилсиликатом (с содержанием $\mathrm{SiO}_{2} 32$ мас. \%) с последующей сушкой образцов при $120^{\circ} \mathrm{C}$ в течение 12 ч и прокаливанием при $500^{\circ} \mathrm{C}$ в течение 2 ч. Далее образцы восстанавливали в токе $\mathrm{H}_{2}\left(30 \mathrm{~cm}^{3} /\right.$ мин-гкат) при $500{ }^{\circ} \mathrm{C}$ в кварцевом реакторе, выдерживали при данной температуре 1 ч $\left(\mathrm{H}_{2}-15 \mathrm{~cm}^{3} /\right.$ мин·Г гат), после чего охлаждали и пассивировали

Таблица 1. Характеристики используемых катализаторов*

Table 1. Characteristics of the used catalysts*

\begin{tabular}{|c|c|c|c|c|c|c|c|c|c|}
\hline \multirow[t]{2}{*}{ Катализатор } & \multicolumn{4}{|c|}{$\begin{array}{c}\text { Состав катализаторов, } \\
\text { мас. } \%\end{array}$} & \multirow{2}{*}{$\begin{array}{l}\text { Mo/Ni } \\
\text { атомн. } \\
\text { отнош. }\end{array}$} & \multirow[t]{2}{*}{$\mathrm{S}_{\mathrm{BET}}, \mathrm{M}^{2} / \Gamma$} & \multirow{2}{*}{$\mathrm{V}_{\Sigma}, \mathrm{cm}^{3} / \Gamma$} & \multirow{2}{*}{$\begin{array}{l}\mathrm{V}_{\text {микро, }}, \\
\mathrm{CM}^{3} / \Gamma\end{array}$} & \multirow{2}{*}{$<\mathrm{d}>_{\text {пор }}, \AA$} \\
\hline & $\mathrm{Ni}$ & $\mathrm{Cu}$ & Mo & $\mathrm{Si}$ & & & & & \\
\hline $\mathrm{NiCu} / \mathrm{SiO}_{2}$ & 56 & 8,2 & - & 18,2 & - & 174,6 & 0,21 & 0,01 & 48 \\
\hline $\mathrm{NiCuMo} / \mathrm{SiO}_{2}-1$ & 49 & 7,1 & 8,8 & 15,8 & 0,11 & 115,0 & 0,22 & 0,01 & 83 \\
\hline $\mathrm{NiCuMo} / \mathrm{SiO}_{2}-2$ & 46 & 6,7 & 11,7 & 15,0 & 0,16 & 109,0 & 0,23 & 0,01 & 83 \\
\hline
\end{tabular}

* $\mathrm{S}_{\mathrm{BET}}$ - площадь удельной поверхности по $\mathrm{BET}, \mathrm{V}_{\Sigma}-$ суммарный объем пор, $\mathrm{V}_{\text {микро }}$ - объем микропор, $<\mathrm{d}>-$ средний размер пор.

смесью $\mathrm{O}_{2}(2 \%) / \mathrm{N}_{2}$. В табл. 1 приведен состав образцов катализаторов.

Удельную поверхность и объем пор катализаторов измеряли методом равновесной адсорбции азота при 77 К на анализаторе удельной поверхности и пористости "Micromeritics ASAP $2020 "$.

\section{3. Термические и термокаталитические эксперименты в сверхкритическом этаноле}

Исследование термического и термокаталитического превращения лигнина при 300 и $350{ }^{\circ} \mathrm{C}$ осуществляли в реакторе C-276 Autoclave Engineers (USA) объемом 100 мл при постоянном перемешивании (800 об/мин) в инертной атмосфере. В реактор загружали 3 г лигнина, 0,3 г катализатора и 30 мл этанола. Затем его герметично закрывали и трижды продували аргоном 
для удаления воздуха. Скорость подъема температуры в автоклаве составляла $8{ }^{\circ} \mathrm{C} /$ мин. За начало процесса принимали момент достижения заданной температуры. Реакцию проводили при постоянном перемешивании со скоростью 800 об/мин в течение 1 ч. Каждый эксперимент осуществляли трижды. Рабочее давление в реакторе 6,3-7,6 МПа в зависимости от используемого катализатора.

После завершения реакции гидрирования и охлаждения реакционной смеси до комнатной температуры газообразные продукты собирали в газометр, определяли их объем и анализировали методом газовой хроматографии. Затем продукты реакции количественно выгружали из автоклава вымыванием этанолом, полученную суспензию жидких и твердых продуктов реакции фильтровали на бумажном фильтре. Твердый остаток на фильтре экстрагировали этанолом, пока экстрагент не станет прозрачным. Фильтрат объединяли с этанольным экстрактом. Из жидких продуктов отгоняли этанол на роторном испарителе, остаток доводили до постоянной массы сушкой под вакуумом (1 мм рт. ст.) при комнатной температуре. Полученный выход фракции жидких продуктов $\left(Y_{l}\right)$ рассчитывали по формуле (1) (мас. \%):

$$
Y_{1}=\frac{m_{1}(g)-m_{k t}(g)}{m_{l}} * 100 \%,
$$

где $m_{l}$ - масса жидких продуктов, $m_{l}$ - органическая масса лигнина.

Выход твердого остатка $\left(Y_{2}\right)$ определяли после удаления растворителя под вакуумом (1 мм рт. ст.) и высушивания при $80{ }^{\circ} \mathrm{C}$ до постоянного веса (мас. \%):

$$
Y_{1}=\frac{m_{1}(g)}{m_{l}} * 100 \%,
$$

где $\mathrm{m}_{2}$ - масса твердого остатка, $\mathrm{m}_{\mathrm{kt}}-$ масса катализатора (г)

Выход газообразного продукта $\left(Y_{3}\right)$ определяли по формуле

$$
Y_{3}=\frac{m_{3}(\mathrm{~g})}{m_{1}} \cdot 100 \%,
$$

где $\mathrm{m}_{3}$ - масса газообразного продукта (г).

\section{4. Исследование состава и строения этаноллигнина}

\section{и жидких продуктов его превращения}

Элементный состав лигнина и жидких продуктов его превращения определяли с использованием анализатора HCNS-O EA FLASH TM 1112 фирмы «Thermo Quest». Этаноллигнин сосны содержит (мас. \%): С - 73,0; Н - 6,6; О - 20,4; золы - 0,2.

Средневесовую $(\mathrm{Mw})$, среднечисловую $(\mathrm{Mn})$ молекулярные массы и полидисперсность (PD) образцов этаноллигнина и жидких продуктов его превращения определяли методом гельпроникающей хроматографии (ГПХ) с использованием хроматографа Agilent 1260 Infinity II Multi-Detector GPC/SEC System с тройным детектированием: рефрактометром (RI), вискозиметром (VS) и светорассеянием (LS). Разделение смесей проводили на двух совмещенных колонках PLgel Mixed-C с использованием в качестве подвижной фазы тетрагидрофурана. Калибровку колонки осуществляли с использованием полидисперсных стандартов 
полистирола (Agilent, США). Скорость подачи элюента - 1 мл/мин, объем вводимой пробы 100 мкл. Перед анализом образцы растворяли в ТГФ (1 мГ/мл) и фильтровали через 0,45 мкм мембранный ПТФЭ-фильтр (Millipore). Сбор и обработку данных выполняли с использованием программного обеспечения Agilent GPC/SEC MDS. Молекулярные массы (Mn, Mw и $\mathrm{PD})$ определяли по калибровочной кривой, полученной с использованием полидисперсных стандартов полистирола.

Газообразные продукты превращения лигнина анализировали на хроматографе «Кристалл-2000», снабженном детектором по теплопроводности. Разделение $\mathrm{CO}$ и $\mathrm{CH}_{4}$ осуществляли на набивной колонке длиной 2 м с цеолитом $\mathrm{NaX}$ в изотермическом режиме при $60{ }^{\circ} \mathrm{C}$. Разделение $\mathrm{CO}_{2}$ и углеводородов проводили на набивной колонке Porapak QP при программировании температуры от 60 до $180{ }^{\circ} \mathrm{C}$ со скоростью подъема температуры $10{ }^{\circ} \mathrm{C} /$ мин.

\section{3. Результаты и обсуждения}

\section{1. Термические и термокаталитические превращения этанола}

Предварительно было проведено исследование термического и термокаталитического превращения сверхкритического этанола. В отсутствие катализаторов даже при температуре $350{ }^{\circ} \mathrm{C}$ наблюдалась низкая конверсия этанола (6 мас. \%). В составе газообразных продуктов в основном входили этилен и этан, а также в небольших количествах (менее 4 об. \%) пропилен и пропан. В присутствии катализаторов конверсия этанола заметно увеличилась. При температуре процесса $300{ }^{\circ} \mathrm{C}$ конверсия этанола составила 15 мас. \%. Основным направлением превращения этанола в присутствии катализатора $\mathrm{NiCu} / \mathrm{SiO}_{2}$ является образование n-бутанола, в присутствии катализаторов с добавлением молибдена - 1,1-диэтоксиэтана. При увеличении температуры до $350{ }^{\circ} \mathrm{C}$ конверсия варьировалась в интервале 21-35 мас. \% в зависимости от типа используемого катализатора. Выходы газообразных продуктов увеличились не существенно (4,0 - 5,6 мас. \%). В составе жидких продуктов в этих условиях детектировано около 25 соединений, доминирующим из которых являлся 1,1-диэтоксиэтан.

\section{2. Конверсия этаноллигнина в сверхкритическом этаноле}

Результаты исследования влияния катализаторов $\mathrm{NiCu} / \mathrm{SiO}_{2}$ и $\mathrm{NiCuMo} / \mathrm{SiO}_{2}$ на выход продуктов термического превращения этаноллигнина сосны в сверхкритическом этаноле (табл. 2) показали, что при температуре $250{ }^{\circ} \mathrm{C}$ катализаторы оказывают незначительное влияние на выходы твердых, жидких и газообразных продуктов.

При температуре $300{ }^{\circ} \mathrm{C}$ в присутствии катализатора $\mathrm{NiCu} / \mathrm{SiO}_{2}$ выход жидких продуктов увеличивается с 63,4 до 78,0 мас. \% по сравнению с некаталитическим процессом. Введение Мо в состав катализатора в количестве 8,8 и 11,7 мас. \% приводит к увеличению выхода жидких продуктов до 83,0 мас. \%, что почти на 20 мас. \% выше, чем в некаталитическом эксперименте (табл. 2). При повторном использовании катализаторов после регенерации существенного снижения выхода жидких продуктов из лигнина не наблюдается.

Газообразные продукты конверсии лигнина содержат в основном оксиды углерода и метан, что находится в соответствии с данными работ [22, 23]. Выход твердого продукта в присутствии катализаторов уменьшается значительно: для $\mathrm{NiCu} / \mathrm{SiO}_{2}-$ более чем в 2 раза; для

$$
-253-
$$


Таблица 2. Выходы продуктов термического и термокаталитического превращения этаноллигнина сосны в сверхкритическом этаноле

Table 2. Yields of products of thermal and thermocatalytic conversion of pine ethanol lignin in supercritical ethanol

\begin{tabular}{|c|c|c|c|c|c|c|c|}
\hline \multirow{3}{*}{$\mathrm{T},{ }^{\circ} \mathrm{C}$} & \multirow{3}{*}{ Катализатор } & \multicolumn{6}{|c|}{ Выход продуктов, мас. \% } \\
\hline & & \multirow{2}{*}{ жидкие } & \multirow{2}{*}{ твердые } & \multicolumn{4}{|c|}{ газообразные } \\
\hline & & & & $\mathrm{CO}$ & $\mathrm{CO}_{2}$ & $\mathrm{CH}_{4}$ & Сумма \\
\hline \multirow{3}{*}{250} & б/кт & 68,2 & 29,5 & $<0,1$ & $<0,1$ & $<0,1$ & 0,1 \\
\hline & $\mathrm{NiCu} / \mathrm{SiO}_{2}$ & 68,9 & 27,1 & 0,3 & 0,1 & 0,2 & 0,6 \\
\hline & $\mathrm{NiCuMo} / \mathrm{SiO}_{2}-1$ & 69,4 & 26,3 & 0,2 & 0,1 & 0,1 & 0,4 \\
\hline \multirow{6}{*}{300} & б/кт & 63,4 & 31,8 & $<0,1$ & 0,1 & 0,1 & 0,3 \\
\hline & $\mathrm{NiCu} / \mathrm{SiO}_{2}$ & 78,0 & 15,8 & 3,4 & 1,2 & 2,4 & 7,0 \\
\hline & $\mathrm{NiCuMo} / \mathrm{SiO}_{2}-1$ & 83,5 & 7,9 & 2,3 & 1,6 & 2,1 & 6,0 \\
\hline & $\mathrm{NiCuMo} / \mathrm{SiO}_{2}-2$ & 83,0 & 8,9 & 2,2 & 1,7 & 2,0 & 5,9 \\
\hline & $\mathrm{NiCu} / \mathrm{SiO}_{2} *$ & 75,5 & 14,5 & 3,6 & 0,8 & 2,9 & 7,3 \\
\hline & $\mathrm{NiCuMo} / \mathrm{SiO}_{2}-1^{*}$ & 80,9 & 9,7 & 3,0 & 1,3 & 2,7 & 7,0 \\
\hline \multirow{4}{*}{350} & б/кт & 51,1 & 44,7 & 1,0 & 0,5 & 0,9 & 2,4 \\
\hline & $\mathrm{NiCu} / \mathrm{SiO}_{2}$ & 80,6 & 1,0 & 7,1 & 1,9 & 3,5 & 11,5 \\
\hline & $\mathrm{NiCuMo} / \mathrm{SiO}_{2}-1$ & 82,5 & 0,8 & 5,0 & 2,4 & 3,3 & 10,7 \\
\hline & $\mathrm{NiCuMo} / \mathrm{SiO}_{2}-2$ & 77,9 & 6,3 & 4,5 & 2,7 & 3,0 & 10,2 \\
\hline
\end{tabular}

*Регенерированный катализатор.

Мо-содержащих катализаторов - в 3,5-4,0 раза. Повышение активности $\mathrm{NiCu-катализаторов}$ при введении молибдена наблюдалось в работе [24] для реакции гидродеоксигенации гваякола.

При температуре процесса $350^{\circ} \mathrm{C}$ в присутствии катализаторов $\mathrm{NiCu} / \mathrm{SiO}_{2}$ и $\mathrm{NiCuMo} / \mathrm{SiO}_{2}-1$ с содержанием Мо 8,8 мас. \% этаноллигнин сосны практически полностью превращается в жидкие и газообразные продукты, выход твердых продуктов не превышает 1 мас. \%. Одновременно несколько снижается выход жидких продуктов по сравнению с соответствующими показателями, полученными при $300^{\circ} \mathrm{C}$, очевидно, в результате их превращения в газы, выходы которых в присутствии катализаторов составляют более 10 мас. \%. Увеличение содержания Мо в катализаторе $\mathrm{NiCuMo} / \mathrm{SiO}_{2}$ до 11,7 мас. \% приводит к снижению выхода жидких продуктов, по-видимому, в результате их вторичной полимеризации, на что указывает увеличение выхода твердого остатка до 6,3 мас. \%. Эти процессы могут катализировать кислотные центры, образованные ионами Mo(IV) и Mo(V), находящимися на поверхности катализатора [24].

Дальнейшее увеличение температуры процесса до $400{ }^{\circ} \mathrm{C}$ приводит к интенсификации реакций превращения жидких продуктов в газ и твердый остаток, выход которых достигает 25,0 и 49,0 мас. $\%$ соответственно.

\section{3. Исследование жидких продуктов конверсии этаноллигнина соснь}

\section{методами элементного анализа и ГПХ}

Результаты исследования этаноллигнина и этанолрастворимых жидких продуктов его термопревращения методом элементного анализа представлены на рис. 1. В жидких продуктах 
наблюдается значительное снижение атомного отношения $\mathrm{O} / \mathrm{C}$ по сравнению с исходным этаноллигнином. Кроме того, для жидких продуктов, полученных в присутствии катализаторов, наблюдается увеличение атомного отношения Н/C с увеличением температуры процесса. Максимальное его значение $(1,42)$ отмечено для жидких продуктов конверсии лигнина в присутствии катализатора $\mathrm{NiCuMo} / \mathrm{SiO}_{2}-2$. Наблюдаемые закономерности в изменении состава жидких продуктов связаны с протеканием реакций деоксигенации и гидрирования лигнина и продуктов его деполимеризации в присутствии твердых катализаторов [25]. Источником активного водорода в условиях исследуемого процесса терморастворения лигнина может служить этанол $[11,16]$.

На рис. 2 и 3 приведены дифференциальные кривые молекулярно-массового распределения для жидких продуктов, полученных в процессе термопревращения этаноллигнина сосны при 300 и $350{ }^{\circ} \mathrm{C}$ в присутствии катализаторов $\mathrm{NiCu} / \mathrm{SiO}_{2}, \mathrm{NiCuMo} / \mathrm{SiO}_{2}-1$. Для сопоставления приведена дифференциальная кривая для исходного лигнина, характеризующаяся следующими параметрами: среднечисловая молекулярная масса (Mn) 741 Да, средневесовая молекулярная масса (Mw) Да 1956 и дисперсность (D) 2,64. Данные распределения молекулярной массы представлены от 150 Да, поскольку молекулы с меньшей молекулярной массой лежат за пределами калибровки хроматографической системы. По сравнению с исходным лигнином в жидких продуктах его термокаталитической конверсии при $300{ }^{\circ} \mathrm{C}$ появляются пики с максимумами в областях 160 и 380 Да, относящиеся к гваяцильным мономерам и димерам соответственно. Это можно объяснить наличием в жидких продуктах веществ с низкой молекулярной

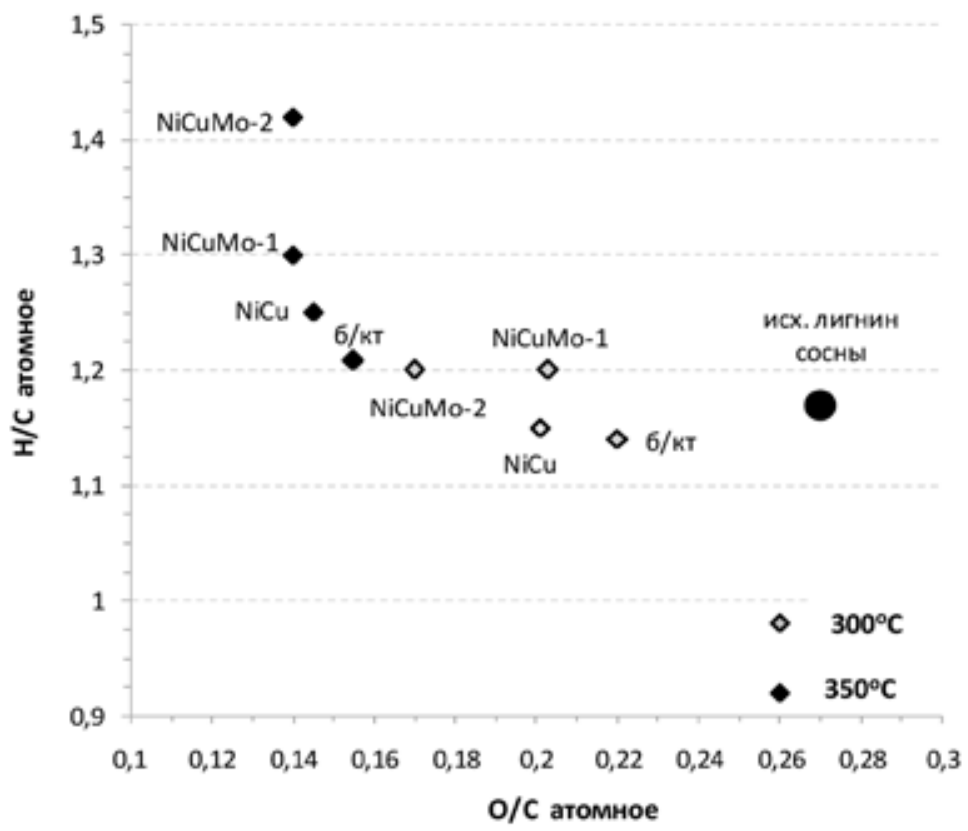

Рис. 1. Диаграмма Ван-Кревелена для жидких продуктов, полученных из этаноллигнина сосны при 300 и $350{ }^{\circ} \mathrm{C}$ в присутствии катализаторов $\mathrm{NiCu} / \mathrm{SiO}_{2}$ и $\mathrm{NiCuMo} / \mathrm{SiO}_{2}$ с различным содержанием Мо

Fig. 1. The Van Crevelen diagram for liquid products obtained from pine ethanol lignin in the presence of $\mathrm{NiCu} /$ $\mathrm{SiO}_{2}$ and $\mathrm{NiCuMo} / \mathrm{SiO}_{2}$ catalysts with different Mo contents at 300 and $350{ }^{\circ} \mathrm{C}$ 


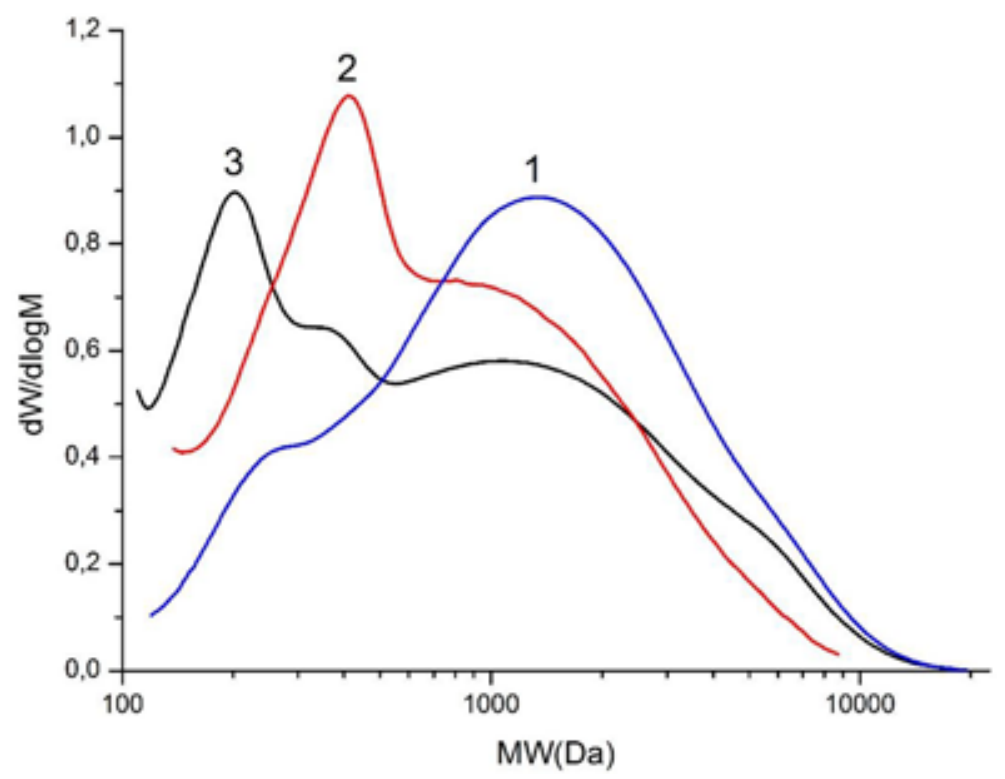

Рис. 2. Дифференциальные кривые молекулярно-массового распределения для исходного этаноллигнина сосны (1) и жидких продуктов, полученных при $300{ }^{\circ} \mathrm{C}$ в присутствии катализаторов $\mathrm{NiCu}_{2} \mathrm{SiO}_{2}(2)$, катализатора $\mathrm{NiCuMo} / \mathrm{SiO}_{2}-1$ (3)

Fig. 2. Differential molecular weight distribution curves for the initial pine ethanol lignin (1) and liquid products obtained in the presence of $\mathrm{NiCu} / \mathrm{SiO}_{2}$ catalysts (2), $\mathrm{NiCuMo} / \mathrm{SiO}_{2}-1$ catalyst (3) at $300{ }^{\circ} \mathrm{C}$

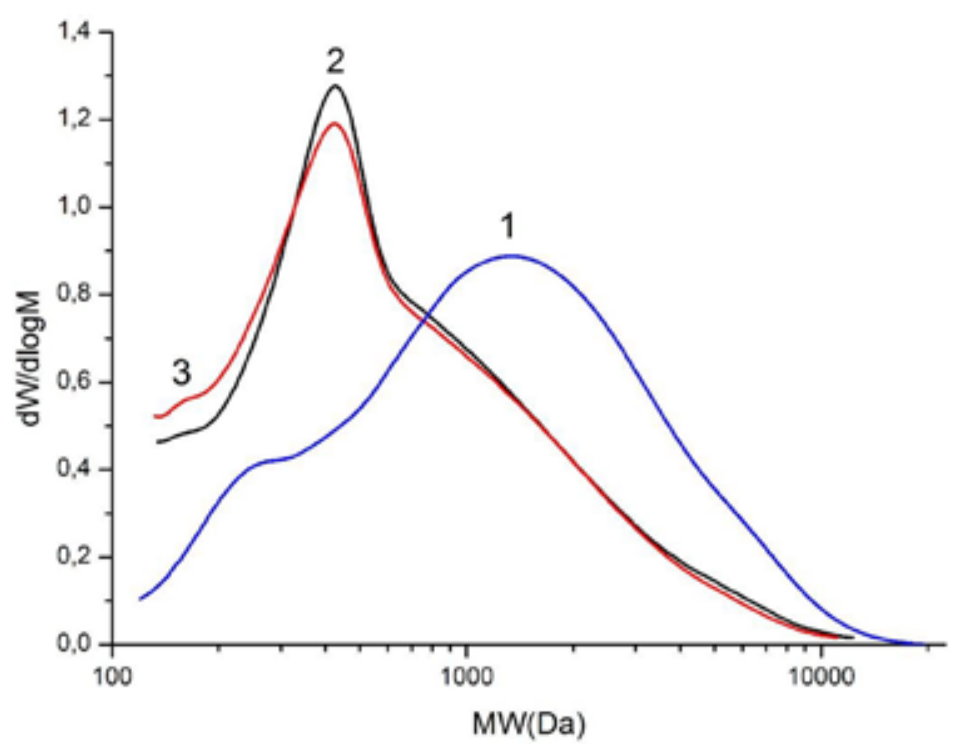

Рис. 3. Дифференциальные кривые молекулярно-массового распределения для исходного этаноллигнина сосны (1) и жидких продуктов, полученных при $350{ }^{\circ} \mathrm{C}$ в присутствии катализаторов $\mathrm{NiCu} / \mathrm{SiO}_{2}(2)$, катализатора $\mathrm{NiCuMo} / \mathrm{SiO}_{2}-1$ (3)

Fig. 3. Differential molecular weight distribution curves for the initial pine ethanol lignin (1) and liquid products obtained in the presence of $\mathrm{NiCu} / \mathrm{SiO}_{2}$ catalysts (2), $\mathrm{NiCuMo} / \mathrm{SiO}_{2}-1$ catalyst (3) at $350{ }^{\circ} \mathrm{C}$ 
массой (рис. 2). Наиболее интенсивный пик при 380 Да характерен для жидких продуктов, полученных в присутствии катализаторов $\mathrm{NiCu} / \mathrm{SiO}_{2}$. Добавки Мо к катализатору приводят к появлению дополнительного интенсивного пика при 160 Да и снижению интенсивности пика при 380 Да. Этот факт указывает на то, что при введении молибдена в состав катализатора реакции деполимеризации этаноллигнина протекают более интенсивно с образованием большого количества мономерных гваяцильных соединений.

На дифференциальной кривой молекулярно-массового распределения жидких продуктов, полученных термокаталитической конверсией лигнина при $350{ }^{\circ} \mathrm{C}$, присутствует только один интенсивный пик с максимумом при 380 Да (рис. 3). Наблюдаемые изменения в ММР жидких продуктов, полученных при температурах 300 и $350{ }^{\circ} \mathrm{C}$ в присутствии катализатора $\mathrm{NiCuMo-1,} \mathrm{указывают} \mathrm{на} \mathrm{интенсификацию} \mathrm{процессов} \mathrm{вторичного} \mathrm{превращения} \mathrm{и} \mathrm{реполиме-}$ ризации продуктов с низкой молекулярной массой при повышении температуры процесса до $350{ }^{\circ} \mathrm{C}$.

\section{Заключение}

В процессе термокаталитического превращения этаноллигнина сосны в сверхкритическом этаноле сопоставлены каталитические свойства катализаторов $\mathrm{NiCu} / \mathrm{SiO}_{2}$ и $\mathrm{NiCuMo} / \mathrm{SiO}_{2}$ с различным содержанием молибдена. При температуре $250{ }^{\circ} \mathrm{C}$ катализаторы не оказывают значительного влияния на конверсию этаноллинина. Максимальный выход жидких продуктов (83,5 мас. \%) получен при температуре процесса $300{ }^{\circ} \mathrm{C}$ в присутствии $\mathrm{NiCuMo} / \mathrm{SiO}_{2}-1$ с содержанием Мо 8,8 мас. \%. В отсутствие катализаторов в этих условиях выход жидких продуктов составил 63,4 мас. \%. Минимальный выход твердого остатка 1 мас. \% получен при $350{ }^{\circ} \mathrm{C}$ в присутствии катализаторов $\mathrm{NiCu} / \mathrm{SiO}_{2}$ и $\mathrm{NiCuMo} / \mathrm{SiO}_{2}-1$. Увеличение температуры до $400{ }^{\circ} \mathrm{C}$ интенсифицирует реакции вторичного превращения жидких продуктов в газ и кокс.

В процессе конверсии этаноллигнина при $300{ }^{\circ} \mathrm{C}$ в присутствии $\mathrm{NiCuMo} / \mathrm{SiO}_{2}$ снижается атомное отношение $\mathrm{O} / \mathrm{C}$ и $\mathrm{H} / \mathrm{C}$ в составе жидких продуктов по сравнению с исходным этаноллигнином. Максимальное значение отношения $\mathrm{H} / \mathrm{C}-1,4$ и минимальное значение отношения $\mathrm{O} / \mathrm{C}-0,14$ получены в присутствии катализатора $\mathrm{NiCuMo} / \mathrm{SiO}_{2}-2$ с содержанием молибдена 11,7 мас. \%.

По данным ГПХ, в жидких продуктах термокаталитичской конверсии этаноллигнина при $300{ }^{\circ} \mathrm{C}$ появляются пики с максимумами в областях 160 и 380 Да, вероятно, отноящиеся к гваяцильным мономерам и димерам соответственно.

Из сопоставления молекулярно-массового распределения жидких продуктов, полученных деполимеризацией этаноллигнина при $300{ }^{\circ} \mathrm{C}$ на катализаторах $\mathrm{NiCu} / \mathrm{SiO}_{2}$ и $\mathrm{NiCuMo} / \mathrm{SiO}_{2}$, следует, что введение молибдена в состав катализатора интенсифицирует реакции образования мономерных гваяцильных продуктов. При повышении температуры процесса до $350{ }^{\circ} \mathrm{C}$ интенсифицируются реакции вторичного превращения и реполимеризации низкомолекулярных жидких продуктов.

\section{Благодарности / Acknowledgements}

Работа выполнена при финансовой поддержке гранта РФФИ № 18-53-16001 в рамках государственного задания ИХХТ СО РАН (Проект АААА-А17-117021310218-7) (V.46.4.3) с ис-

$$
-257-
$$


пользованием оборудования Красноярского регионального центра коллективного пользования ФИЦ КНЦ СО РАН.

This work was supported by the RFBR grant No. 18-53-16001 within the framework of the state assignment of the Institute of Chemistry and Chemical Technology SB RAS (Project AAAA-A17-117021310218-7) (V.46.4.3) using the equipment of Krasnoyarsk Regional Research Equipment Centre of SB RAS.

\section{Список литературы / References}

1. Zhou C.-H., Xia X., Lin C.-X., Tong D.-S., Beltramini J. Catalytic conversion of lignocellulosic biomass to fine chemicals and fuels. Chemical Society Reviews. 2011. Vol. 40(11), P. 5588-5617.

2. Xu C., Arancon R.A.D., Labidi J., Luque R. Lignin depolymerisation strategies: towards valuable chemicals and fuels. Chemical Society Reviews. 2014. Vol. 43(22), P. 7485-7500.

3. Nelson V. Introduction to Renewable Energy. CRC Press. 2011, P. 384 p.

4. Kim J.-Y., Oh S., Hwang H., Cho T.-S., Choi I.-G., Weon Choi J. Effects of various reaction parameters on solvolytical depolymerization of lignin in sub- and supercritical ethanol. Chemosphere. 2013. Vol. 93, P. 1755-1764.

5. Pandey M.P., Kim C.S. Lignin Depolymerization and Conversion: A Review of Thermochemical Methods. Chemical Engineering \& Technology. 2011. Vol. 34(1), P. 29-41.

6. Galkin M.V., Smit A.T., Subbotina E., Artemenko K.A., Bergquist J., Huijgen W.J.J., Samec J.S.M. Hydrogen-free catalytic fractionation of woody biomass. ChemSusChem. 2016. Vol. 9(23), P. 3280-3287.

7. Sun Z., Fridrich B., de Santi A., Elangovan S., Barta K. Bright Side of Lignin Depolymerization: Toward New Platform Chemicals. Chemical Reviews. 2018. Vol. 118(2), P. 614-678.

8. Zakzeski J., Bruijnincx P.C.A., Jongerius A.L., Weckhuysen B.M. The Catalytic Valorization of Lignin for the Production of Renewable Chemicals. Chemical Reviews. 2010. Vol. 110(6), P. 35523599 .

9. Zhang K., Pei Z.J., Wang D. Organic solvent pretreatment of lignocellulosic biomass for biofuels and biochemicals: A review. Bioresour. Technol. 2015. Vol. 199, P. 21-33.

10. Kuznetsov B.N., Sharypov V.I., Chesnokov N.V., Beregovtsova N.G., Baryshnikov S.V., Lavrenov A.V., Vosmerikov A.V. Lignin Conversion in Supercritical Ethanol in the Presence of Solid Acid Catalysts. Kinetika i Kataliz. 2015. Vol. 56(4), P. 8.

11. Macala G.S., Matson T.D., Johnson C.L., Lewis R.S., Iretskii A.V., Ford P.C. Hydrogen Transfer from Supercritical Methanol over a Solid Base Catalyst: A Model for Lignin Depolymerization. ChemSusChem. 2009. Vol. 2(3), P. 215-217.

12. Løhre C., Barth T., Kleinert M. The effect of solvent and input material pretreatment on product yield and composition of bio-oils from lignin solvolysis. Journal of Analytical and Applied Pyrolysis. 2016. Vol. 119, P. 208-216.

13. Huang X., Korányi T.I., Boot M.D., Hensen E.J.M. Catalytic Depolymerization of Lignin in Supercritical Ethanol. ChemSusChem. 2014. Vol. 7(8), P. 2276-2288.

14. Ennaert T., Van Aelst J., Dijkmans J., De Clercq R., Schutyser W., Dusselier M., Verboekend D., Sels B.F. Potential and challenges of zeolite chemistry in the catalytic conversion of biomass. Chemical Society Reviews. 2016. Vol. 45(3), P. 584-611. 
15. Wang H., Tucker M., Ji Y. Recent Development in Chemical Depolymerization of Lignin: A Review. Journal of Applied Chemistry. 2013. Vol. 2013, P. 1-9.

16. Kim J.-Y., Park J., Hwang H., Kim J.K., Kyu Song I., Weon Choi J. Catalytic depolymerization of lignin macromolecule to alkylated phenols over various metal catalysts in supercritical tert-butanol. Journal of Analytical and Applied Pyrolysis. 2014. Vol. 113, P. 99-106.

17. Ermakova M.A., Ermakov D.Y. High-loaded nickel-silica catalysts for hydrogenation, prepared by sol-gel: Route: structure and catalytic behavior. Applied Catalysis A: General. 2003. Vol. 245(2), P. 277-288.

18. Bykova M.V., Ermakov D.Y., Khromova S.A., Smirnov A.A., Lebedev M.Y., Yakovlev V.A. Stabilized Ni-based catalysts for bio-oil hydrotreatment: Reactivity studies using guaiacol. Catalysis Today. 2014. Vol. 220-222, P. 21-31.

19. Шарыпов В.И., Кузнецов Б.Н., Яковлев В.А., Береговцова Н.Г., Барышников С.В., Дьякович Л., Пинель К. Состав жидких продуктов конверсии ацетонлигнина в сверхкритическом бутаноле в присутствии катализаторов $\mathrm{NiCu} / \mathrm{SiO}_{2}$. Журнал Сибирского федерального университета. Химия. 2015. T. 8(3), C. 465-475. [Sharypov V.I., Kuznetsov B.N., Yakovlev V.A., Beregovtsova N.G., Baryshnikov S.V., Djakovitch L., Pinel C. Composition of Liquid Products of Acetonlignin Conversion Over $\mathrm{NiCu} / \mathrm{SiO}_{2}$ Catalysts in Supercritical Butanol. Journal of Siberian Federal University. Chemistry. 2015. Vol. 8(3), P. 465-475 (In Russ.)]

20. Шарыпов В.И., Кузнецов Б.Н., Яковлев В.А., Береговцова Н.Г., Барышников С.В. Исследование термической конверсии ацетонлигнина в сверхкритическом бутаноле в присутствии катализаторов $\mathrm{NiCuMo/SiO2.} \mathrm{Катализ} \mathrm{в} \mathrm{промышленности.} \mathrm{2017.} \mathrm{T.} \mathrm{17(1),} \mathrm{C.} \mathrm{60-69.} \mathrm{[Sharypov} \mathrm{V.I.,}$ Kuznetsov B.N., Yakovlev V.A., Beregovtsova N.G., Baryshnikov S.V. Studies of Thermal Conversion of Acetonelignin in Supercritical Butanol in the Presence of $\mathrm{NiCuMo} / \mathrm{SiO}_{2}$ Catalysts. Kataliz $v$ promyshlennosti. 2017. Vol. 17(1), P. 60-69. (In Russ.)]

21. Arato C., Kendall Pye E., Gjennestad G. The Lignol Approach to Biorefining of Woody Biomass to Produce Ethanol and Chemicals. Applied biochemistry and biotechnology 2005. Vol. 123, P. 871-882.

22. Grilc M., Likozar B., Levec J. Simultaneous Liquefaction and Hydrodeoxygenation of Lignocellulosic Biomass over NiMo/A12O3, Pd/A12O3, and Zeolite Y Catalysts in Hydrogen Donor Solvents. ChemCatChem. 2016. Vol. 8(1), P. 180-191.

23. Feng P., Wang H., Lin H., Zheng Y. Selective production of guaiacol from black liquor: Effect of solvents. Carbon Resources Conversion. 2019. Vol. 2(1), P. 1-12.

24. Alekseeva M.V., Rekhtina M.A., Lebedev M.Y., Zavarukhin S.G., Kaichev V.V., Venderbosch R.H., Yakovlev V.A. Hydrotreatment of 2-Methoxyphenol over High Ni-Loaded Sol-Gel Catalysts: The Influence of Mo on Catalyst Activity and Reaction Pathways. Chemistry Select. 2018. Vol. 3(18), P. 5153-5164.

25. Sturgeon M., O’Brien M., N. Ciesielski P., Katahira R., S. Kruger J., C. Chmely S., Hamlin J., Lawrence K., B. Hunsinger G., Foust T., M. Baldwin R., J. Biddy M., Beckham G. Lignin depolymerisation by nickel supported layered-double hydroxide catalysts. Green Chemistry 2014. Vol. 16(2), P. 824-835. 